Адрес статьи / To link this article: http://cat.itmo.ru/ru/2021/v6-i1/258

\title{
Краеведение online: история одного микрорайона в социальной сети
}

\author{
Л.Б. Краева \\ Университет ИТМО, Россия \\ lbkraeva@itmo.ru
}

\begin{abstract}
Аннотация. Данная статья анализирует контент сообществ социальной сети «В контакте», посвященных микрорайону «Форель», он же Кировский жилгородок в Санкт-Петербурге (место историческое, но не туристическое) - это сообщества « ФАРЕЛЬ ЦЫ », [https://vk.com/club123762], и «микрорайон «Форель» Кировский городок СПб» [https://vk.com/foreal]. Если указывать не электронный адрес, а фактический, то микрорайон ограничен улицами Зины Портновой, Трамвайным проспектом, Ленинским проспектом и проспектом Стачек. Также анализируется краеведческая рефлексия на уровне исторической информации в группах и на уровне герменевтического контекста обсуждений и постов. В статье применяется анализ документов (цифрового контента групп), археографический метод, герменевтический метод, метод этнометодологии Г. Гарфинкеля.
\end{abstract}

Ключевые слова: digital краеведение, урбанистика, локальная идентичность

Базой для создания сообществ социальной сети стал именно исторический аспект этого места, его трансформация из пригородной усадьбы, заложенной ещё Б. Растрелли, в больничный комплекс «Всех скорбящих радости», после революции переименованный в больницу им. А. Фореля, затем жилой микрорайон. Информация в группах состоит из объективного и субъективного содержания. Объективное содержание - это исторические факты, краеведческая информация групп. Субъективная информация отражает событийный, повседневный аспект жизни микрорайона, отраженный в обсуждениях, запросах, комментариях, объявлениях, воспоминаниях, стихотворном творчестве участников группы. Объективная информация выступает герменевтическим фоном для субъективной рефлексии, являющейся ярким примером коллективных практик локальной идентичности. Герменевтика, как наука о чтении текстов, предполагает прочтение текста с учётом исторических, культурных и бытовых обстоятельств их создания. Герменевтический фон тем и обсуждений исследуется с помощью этнометодологии, которая предполагает наличие обстоятельств и фактов, которые не требуется дополнительно проговаривать, чтобы был понятен контекст представленной информации.

Цифровой образ «объективной» истории жилгородка включает и историю архитектуры от Б. Растрелли до Л. Шретера, и эволюцию его социального предназначения, и память о его героической роли в годы блокады Ленинграда как оборонительного сооружения, которое 
захватчики не смогли преодолеть, и реконструкцию, новое строительство в послевоенные годы как жилого микрорайона.

Эволюция социального предназначения, смена социальных ролей проходила в несколько этапов: загородная усадьба с парком и угодьями, больница для умалишенных, крепость на линии фронта, форпост в обороне Ленинграда и послевоенный жилгородок. Первое предназначение этого места - загородная усадьба, дворцово-парковый комплекс. Владельцами усадьбы в разное время были Головины и Нарышкины, К.Е. Сиверс, Г.А. Потёмкин, К.А. Остерман, а с 1828 года усадьба стала казённым учреждением. При К.Е. Сиверсе на территориях у Петергофской дороги стали возводить роскошный загородный особняк под руководством Ф.Б. Растрелли. Каменный дом, выполненный в лучших традициях стиля барокко, стал одним из поздних творений великого зодчего. Представление о внешнем виде данной постройки можно составить по предварительным чертежам и зарисовкам Ф.Б. Растрелли, которые в наше время находятся в фондах Национальной библиотеки в Варшаве. Дом был одноэтажным, его главными украшениями служил высокий мезонин и подъезд с двумя пандусами, оформленный композициями из колонн (подробнее можно почитать в труде историка С. Горбатенко [5]). Дачу Сиверса любила посещать императрица Екатерина Великая, и впоследствии, в 1779 году, усадьба была куплена Г.А. Потёмкиным, который за недолгое время своего владения усадьбой трансформировал парковый ландшафт. По его заказу на создание английского парка садовник Вильям Гульд создал красивый парк с оригинальной и сложной системой прудов, соединённых дуговым каналом. В дальнейшем усадьба перешла в собственность канцлера И.А. Остермана, при котором она была перестроена в стиле классицизма.

Второй период в развитии усадебного дворцово-паркового обустройства заключается в трансформации его в больничный комплекс, и представляет собой интересный опыт организации медицинской помощи определённого профиля. История больницы для душевнобольных на этом месте начинается с 1828 года, когда императрица Мария Федоровна подписывает в мае 1828 года документ об учреждении штата дома умалишенных на 120 человек. Тогда это заведение отделяется от Обуховской больницы. Мария Федоровна стремилась улучшить положение душевнобольных на примерах организации ухода за такими пациентами в западноевропейских странах. Попечитель заведения Джон Венинг предложил купить дом на одиннадцатой версте Петергофской дороги и приспособить его для нужд больницы, поскольку авторитетные медики того времени считали здание и усадьбу подходящими для данных нужд.

Перестройка и расширение больничного здания производилась с 1828 по 1832 год: сначала к главному зданию по проекту Д. Квадри пристроили флигели, а позднее архитектор П.С. Плавов перестроил и сам дворец, оборудовав в бывшем бальном зале церковь во имя Божьей Матери Всех Скорбящих Радости. В результате множественных пристроек и перепланировок возник состоящий из нескольких корпусов больничный городок. Отношение к пациентам было гуманным, врачи стремились обеспечить индивидуальный подход к пациентам: уютную обстановку (цветы на окнах, картины, камин в курительной комнате). Первым руководителем больницы стал выходец из Саксонии врач Ф.И. Герцог (1784-1853), ранее работавший психиатром в Москве. Благодаря покровительству императрицы Марии Федоровны больница считалась одной из самых приличных казенных больниц, и даже одной из лучших в Европе. Неудивительно, что вскоре она оказалась переполненной. В числе её пациентов находилось немало хроников, за которыми в домашних условиях трудно было обеспечить должный уход. Уже через несколько лет к ней пристроили новый корпус на 80 кроватей, но и это не решило проблемы.

В конце XIX века в больнице было 300 кроватей - 150 для мужчин и столько же для женщин. Кроме того, при ней осуществлялся амбулаторный приём для бедных больных, страдающих разными болезнями, которых ежегодно обращалось до 3 тысяч. Принимали в больницу «лиц всякого звания». Из общего числа мест 160 были платные: для людей с ограниченными средствами плата составляла 10 рублей в месяц; для пациентов, помещаемых государственными и общественными учреждениями - 20 рублей; для своекоштных полупансионеров - 30, и своекоштных пансионеров - по 60 рублей в месяц. 110 мест являлись бесплатными, включая 10 так называемых запасных кроватей. Здесь (наверное, в корпусе для неизлечимых больных) умер художник Павел Андреевич Федотов, автор «Вдовушки», «Сватовства майора», «Свежего кавалера». Кстати, узнав о болезни художника, Николай I выделил довольно крупную сумму на его лечение, но это не помогло. [Пост в сообществе

Культура и технологии, Том 6, № 1 
социальной сети «в контакте» «Питер. Взгляд назад», https://vk.com/wall-98221_6436409?w=wall98221643-6409]. Весьма любопытны сведения о штате больницы. Медицинский персонал состоял из 7 врачей, 6 фельдшеров, аптекаря, аптекарского ученика и фельдшера при аптеке. Административный персонал был представлен смотрителем, бухгалтером, письмоводителем, помощником смотрителя, 2 писцами, священником, псаломщиком и архитектором. Ухаживали за больными 4 надзирателя и 3 надзирательницы, 11 их помощников, кастелянша, 40 служителей, 41 сиделка и по хозяйственной части 92 человека.

В больничном уставе утверждались гуманные принципы обращения с душевнобольными, и были сформулированы первые предложения по внедрению рациональной терапии занятостью. Автором больничного устава, регламентирующего работу заведения и основывавшегося на гуманных принципах обращения с душевнобольными, стал врач Иоханн Георг Рюль (1769-1846). Получив медицинское образование в Германии, он поступил на службу в Россию. Свою практику в области психиатрии он наработал в Обуховской больнице в Санкт-Петербурге, и, будучи лейбмедиком вдовствующей императрицы Марии Федоровны, стал её доверенным советником по медицинским вопросам.

После революции больница была названа в честь швейцарского психиатра Огюста Анри Фореля (1848-1931). Личность и теоретические изыскания этого учёного интересны хотя бы в силу того, что его имя стало бытовым названием микрорайона. В контенте сообществ указывается имя Фореля, обстоятельства переименования больницы, связанные с его дружбой с А.В. Луначарским, но подробности не указываются, хотя смысловое появление этого имени в топонимике не случайно. Август Форель был сторонником социалистического устройства общества, считал, что оно наиболее близко к природе человека, и вполне соответствует человеческим социальным инстинктам. Этот учёный, объявив пьянство и другие виды зависимого поведения не пороком, а болезнью, предлагал инновационные методы лечения, а также пропагандировал трезвый образ жизни, утверждая, что здоровье общества зависит от ситуационного выбора каждого человека на несколько поколений вперёд [2].

В его теории девиантного поведения было оригинальное объяснение причин отклоняющегося поведения, связанное с понятием «алкогольной бластофтории», предопределяющей девиацию в следующих поколениях. С его точки зрения, социальный, нравственный выбор старшего поколения гарантированно сказывается на физическом, психическом и нравственном здоровье двух последующих поколений. Согласно теории алкогольной бластофтории, если в поколении дедушек-бабушек или родителей выбиралось потребление алкоголя и наркотиков, то это должно сказаться на повреждении формирующихся клеток организма будущих поколений, что станет предпосылкой для возможного девиантного поведения младших поколений. Например, этой теорией А. Форель объяснял появление гомосексуализма как последствия алкоголизма или наркотической зависимости старших поколений. Для предотвращения и преодоления девиантного поведения он предлагал не только традиционные методы социального контроля в виде позитивных и негативных формальных и неформальных санкций, но и инновационные методы лечения. Например, он разрабатывал и внедрял методику медицинского гипноза, которая в современной медицине применяется для «кодирования» пациента с целью избавления от разного рода болезненных зависимостей. Новизна его взглядов проявилась и в том утверждении, что пьянство и алкоголизм - это не только социальные пороки, но и болезнь, которую нужно и можно лечить $[18,19]$. Поэтому нельзя считать случайностью, что профильная больница после революции была названа его именем.

Следующий этап существования этого места связан с трагическим периодом героической обороны Ленинграда в годы Великой Отечественной войны, и этот больничный комплекс стал непреодолимой преградой на пути фашистских захватчиков. В группах опубликованы фотографии военного времени, демонстрирующие серьёзные разрушения, которым подверглись зданий больничного комплекса в результате обстрелов вражеской артиллерии и авиации. Именно эти разрушения предопределили последующую реконструкцию микрорайона в стиле сталинского классицизма как жилищного массива под руководством архитектора Л. Шретера. Визуальное содержание групп наполнено фотографиями домов микрорайона в разные сезоны и при разном освещении, с детализацией архитектурных деталей, от крупных планов до достаточно подробных элементов отделки.

International Culture \& Technology Studies, Vol. 6, No. 1 
Современное предназначение микрорайона связано с жилой застройкой. После войны обсуждался вопрос о реставрации зданий больничного комплекса, но, в связи с острой нехваткой жилья для рабочих района, было принято решение о реконструкции зданий под жилой комплекс для рабочих Кировского завода. В 1950-х годах в архитектурной мастерской № 8 института «Ленпроект» под руководством архитектора Логина Людвиговича Шретера (1908-1988), внука известного зодчего Леонтия Бенуа, был разработан и успешно реализован новый проект. В 1965 году в главном корпусе жилгородка на пр. Стачек, 158, был открыт Дом культуры «Кировец» (см. у Старковой Л.А. [16, 17]). С 1960-х годов площадь микрорайона расширяется за счёт строительства кооперативных домов по проекту Надёжина Н.Н. под руководством В.М. Фромзеля, линейно продолжающих перспективу проспекта. Дома по проекту Николая Николаевича Надёжина (1929-2005), чередующиеся с кирпичными пятиэтажками, так называемые «точки Надёжина» советской серии жилых домов-точек 1-528КП-40, изначально строились для ЖСК в Ленинграде, но потом приобрели распространение и в некоторых других городах. Этот проект отличался определённой оригинальностью на фоне хрущёвской застройки того времени. В 1990 году круглый пруд и отдельные исторические здания Кировского жилгородка были взяты под охрану государства. К 300-летию Санкт-Петербурга была проведена реставрация некоторых зданий, а также масштабная реконструкция придомовых и дворовых территорий.

Цифровой образ «субъективной» истории микрорайона связан с воспоминаниями, цифровым воспроизводством житейских социальных контактов и устойчивых взаимодействий, содержанием сознания участников групп от фотографирования снежинок в свете фонаря или ярких осенних листьев на фоне деталей и элементов неповторимой местной архитектуры, до примеров литературного творчества. Герменевтическая рефлексия включает и воспоминания жителей и бывших жителей микрорайона (старые фотографии, детские фотографии, стихи о детстве в Форели), и обсуждение происшествий и социальных проблем.

Для смыслового анализа данного цифрового контента можно применить принципы этнометодологии Г. Гарфинкеля [3], когда общение и взаимодействие происходит в контексте, который понятен и очевиден «своим», но не объясняется подробно «чужим», поскольку в этом нет необходимости, ведь «чужие» не включены в данное взаимодействие. Контент групп доказывает, что для жителей микрорайона и участников групп в социальных сетях характерна ярко выраженная локальная идентичность, местный патриотизм, осознание некоторой своей исключительности и чётко проговариваемый «этноцентризм», связанный не с этничностью, а с принадлежностью к общему месту проживания с чётко обозначенными границами. Это подтверждается и сквозным мотивом «столичности», «центральности» Форели в обсуждениях и постах (например, тема обсуждения «Форель - как много в этом слове», или в поздравлении местного футбольного клуба своим болельщикам на мотив песни о столице), и трансляции в цифровом виде устойчивых мифов нескольких поколений форельского детства. Например, в устном общении нескольких поколений выросших здесь детей передаётся миф о том, что в дне пруда есть воронка, которая является туннелем в центр Земли, и цифровой контент на темы пруда, и особенно пруда в период реконструкции, когда он временно был осушен, а дно без воронки было зафиксировано на множестве фотографий, парадоксально укрепило эту легенду.

Образ и роль Форели в художественной литературе и кинематографии не проговаривается подробно, а упоминается контекстно, например, когда выкладывается пост с фотографией Андрея Пименова (известного как Кивинова), и вскользь упоминается, что он служил опером в местном отделении полиции и стал одним из сценаристов сериала «Улицы разбитых фонарей», и даже не упоминается название его книги «Кошмар на улице Стачек», хотя книга приобрела популярность и выдержала несколько переизданий с 1994 до 2020 года (например, [7, 8, 9]).

Однако социальные проблемы, даже с очень серьёзными последствиями, в группах представлены непропорционально мало относительно актуального социального запроса. Например, несмотря на значительный период времени, прошедший со времени трагического пожара в доме 1917 года постройки, не решены актуальные проблемы бывших жильцов, и не восстановлено историческое здание. Сразу после пожара, в котором были погибшие, огромное количество чудом спасшихся, пострадавших и потерявших всё имущество и единственное жильё, обсуждения были достаточно подробные, очень многим необходимо было высказаться, обсудить обстоятельства и причины происшедшего, но спустя определённый период времени описание драматических подробностей было удалено из контента групп, и напоминанием о событии остался

Культура и технологии, Том 6, № 1 
только пост о том, что штаб помощи пострадавшим находится в школе микрорайона. Этот контент был удалён, а последствия пожара до сих пор не преодолены, социальные проблемы не решены полностью, здание не восстановлено и подвергается дальнейшим разрушениям, хотя со времени пожара прошло уже больше восьми лет. Это объяснимо тем, что актуальные проблемы редко решаются обсуждениями в социальных сетях, эти посты и комментарии были выплеском эмоций, связанных с преодолением этой ситуации и поисками справедливости, являясь примером событийной коллективной памяти в виртуальном пространстве.

Незначительная доля актуальности практического аспекта контента групп связана, во многом, с тем обстоятельством, что сообщества носят ностальгический характер, потому что состав участников группы и фактическое население микрорайона различаются, в сообществах состоят бывшие жители Форели, давно покинувшие родной микрорайон. Таким образом, эти виртуальные сообщества посвящены в большей степени краеведческому и эстетическому аспектам истории микрорайона, чем актуальному решению социальных проблем, выполняют более «музейные» функции, чем социальные. Тем не менее, анализ контента данных сообществ позволяет утверждать, что они являются ярким примером трансформации коммеморативных практик в виртуальном пространстве.

\section{Литература}

[1] Александров П.П. За Нарвской заставой: воспоминания старого рабочего. Л.: Лениздат, 1963.

[2] Бородин Д.И. Профессор А. Форель по вопросу о борьбе с пьянством. СПб: Типо-Литография Виленчик, 1910.

[3] Гарфинкель Г. Исследования по этнометодологии. СПб: Питер, 2007.

[4] Garfinkel H. Studies in Ethnomethodology. Englwood Cliffs, New Jersey: Prentice-Hall, 1967.

[5] Говорушин К. В. За Нарвской заставой. М.: Политиздат, 1975.

[6] Горбатенко С.Б. Петергофская дорога. Историко-архитектурный путеводитель. СПб: Европейский дом, 2001.

[7] Зуев Г.И. Нарвская застава. На перепутье трёх веков. М.-СПб: Центрполиграф МиМ - Дельта, 2004.

[8] Кивинов А. Кошмар на улице Стачек. М.: АСТ, СПб: Астрель, 2010.

[9] Кивинов А. Кошмар на улице Стачек. М.: Вече, 2017.

[10] Кивинов А. Кошмар на улице Стачек. М.: Центрполиграф, 2020.

[11] King A. The structure of social theory. London, New York: Routledge, 2004.

[12]Кравченко С.А. Социология. Парадигмы через призму социологического воображения. М.: Экзамен, 2002.

[13]Мительман М., Глебов Б., Ульянский А. История Путиловского завода 1789-1917. М.: ОГИЗ Госполитиздат, 1941.

[14]Нарвская застава от истоков до наших дней. Краткий очерк истории Кировского района СанктПетербурга/ [авт. текста Ю. М. Сугоняев; сост.: Л.Н. Егорова]. - Изд. 2-е, доп. - СПб: Лениздат, 2007.

[15]Новые направления в социологической теории. М.: Прогресс, 1978.

[16]Протопопов М.И. Нарвская застава в 1917 году в воспоминаниях и документах. Л.: Лениздат, 1960.

[17] Спасский С.Д., Ульянский А.Г., Вагинов К.К., Чуковский Н.К. Четыре поколения (Нарвская застава). Л.: Издательство писателей, 1933. (В 1961 году эта книга была включена в Сводный список книг, подлежащих исключению из библиотек и книготорговой сети).

[18] Старкова Л.А. История здания Центра культуры и досуга «Кировец». Часть II: откуда в пруду форель. // Нарвская застава, 4 (417)/март/2020.

[19]Старкова Л.А. Прогулки по Нарвской заставе: книга по истории Кировского района. СПб: Изд-во ЦБС Кировского района, 2014.

[20]Форель А. Половой вопрос. СПб: изд. А.С. Суворина, 1906.

[21] Форель А. Половой вопрос. Любовь как извращение. Москва: Алгоритм, 2019.

[22] Forel A. Der Hypnotismus und seine strafrechtliche Bedeutung. Berlin und Leipzig: Guttentag, 1888.

[23] Heritage, J. Garfinkel and Ethnomethodology. Cambridge: Polity press, 1989.

[24]Штомпка П. Визуальная социология. Фотография как метод исследования. Москва: Логос, 2010.

International Culture \& Technology Studies, Vol. 6, No. 1 


\title{
Local History online: the history of a neighborhood in a social network
}

\author{
L.B. Kraeva
}

ITMO University, Russia

\begin{abstract}
This article analyses the content of the communities of the social network "In Contact", dedicated to the little district "Forel", it's so-called "Kirovsky" living-district in St. Petersburg (a historical place, but not a tourist one) - these are the communities " FAREL TSY ", [https://vk.com/club123762], and "little district Forel "Kirovsky Gorodok SPb"" [https://vk.com/foreal]. If you specify an email address, but the actual one, then the neighbourhood is limited to Zina Portnova Street, Tram Avenue, Leninsky Avenue and Stachek Avenue. Local history reflection is also analysed at the level of historical information in groups and at the level of the hermeneutical context of discussions and posts. The article uses the analysis of documents (digital content of groups), the archive-studies method, the hermeneutic method, the method of ethnomethodology of G. Garfinkel. The English abstract for your paper for the embedded multimedia online journal "International Culture \& Technology Studies".
\end{abstract}

Keywords: digital local history; urban studies; local identity.

\section{References}

[1] Alexandrov P.P. Za Narvskoy zastavoy: vospominanija starogo rabochego. [Behind the Narva outpost: memories of an old worker]. L.: Lenizdat, 1963.

[2] Borodin D.I. Professor A. Forel po voprosy o borbe s pjanstvom. [ Professor A. Forel on the fight against drunkenness] SPb: Typo-Lytographia Vilenchik, 1910.

[3] Garfinkel H. Issledovanija po ethnometodologiji. [Studies in Ethnomethodology] SPb: Piter,2007.

[4] Garfinkel H. Studies in Ethnomethodology. Englwood Cliffs, New Jersey: Prentice-Hall, 1967.

[5] Govorushin K.V. Za Narvskoy zastavoy. [Behind the Narva outpost]. M.: Politizdat, 1975.

[6] Gorbatenko S.B. Petergofskaya doroga. Istoricko-architeckturny putevoditel. [Peterhof road. Historical and architectural guide]. SPb: Evropeisky dom, 2001.

[7] Zuev G.I. Narvskaya zastava. Na pereputie trjokh vekov. [ Narva outpost. At the crossroads of three centuries] M. -SPb: Tsentropoligraph MiM - Delta, 2004.

[8] Kivinov A. Koshmar na ulitse Stachek. [Nightmare on Stachek Street]. M.: AST, SPb: Astrel, 2010.

[9] Kivinov A. Koshmar na ulitse Stachek. [Nightmare on Stachek Street]. M.: Veche, 2017.

[10] Kivinov A. Koshmar na ulitse Stachek. [Nightmare on Stachek Street]. M.: Tsenrpoligraph, 2020.

[11] King A. The structure of social theory. London, New York: Routledge, 2004.

[12] Kravchenko S.A. Sociologia. Paradigmy cherez prismu sociologicheskogo voobrazenija. [Sociology. Paradigms through the lens of the sociological imagination]. M.: Examen, 2002.

[13] Mitelman M., Glebov B., Uliansky A. Istoria Putilovskogo zavoda 1789-1917. [History of the Putilov Factory in 1789-1917]. M.: OGIZ - Gospolitizdat, 1941.

[14] Narvskaya zastava ot istokov do nashikh dney. Kratky ocherk istoriji Kirovskogo rayona Sankt-Peterburga. [Narva Outpost from its origins to the present day. A brief sketch of the history of the Kirovsky district of St. Petersburg]. / [avt. texta Y.M. Sugonjaev, sost.: L.N. Egorova]. - isd. 2-e, dop. - SPb: Lenizdat, 2007.

[15] Novye napravlenija v sociologicheskoy teoriji. [New directions in sociological theory]. M.: Progress, 1978.

[16] Protopopov M.I. Narvskaya zastava v 1917 godu v vospominanijakh e dokumentskh. [Narva Outpost in 1917 in memoirs and documents] L.: Lenizdat, 1960.

[17] Spassky S.D., Uliansky A.G., Vaginov K.K., Chukovsky N.K. Chetyre pokolenija (Narvskaja zastava). [ Four generations. (Narva outpost)]. L.: Isdatelstvo pisateley, 1933.

[18] Starkova L.A. Istorija zdanija Centra kultury e dosuga "Kirovetz". Chast II: otkuda v prudu forel. [The history of the building of the Center of Culture and Leisure "Kirovets". Part II: where the trout come from in the pond]. // Narvskaya zastava, 4 (417)/ mart/ 2020.

[19] Starkova L.A. Progulki po Narvskoy zastave: kniga po istoriji Kirovskogo rajona. [Walking along the Narva outpost: a book on the history of the Kirovsky district]. SPb: Isd-vo CBS Kirovskogo rajona, 2014.

[20] Forel A. Polovoy vopros. [The sexual question]. SPb: isd. A.S. Suvorina, 1906.

[21] Forel A. Polovoy vopros. Lubof kak izvrashchenije. [The sexual question. Love as a perversion]. M.: Algoritm, 2019. 
[22]Forel A. Der Hypnotismus und seine strafrechtliche Bedeutung. [Hypnotism and its criminal significance]. Berlin und Leipzig: Guttentag, 1888.

[23] Heritage, J. Garfinkel and Ethnomethodology. Cambridge: Polity press, 1989.

[24] Shtompka P. Visualnaja sociologija. Photographia kak metod issledovanija. [Visual Sociology. Photography as a research method]. M.: Logos, 2010. 